\title{
A IMPORTANCIA DA DISCIPLINA DE HISTÓRIA NO CURRICULO ESCOLAR
}

\section{Viviane dos Santos Fernandes Leão ${ }^{1}$ Ana Enedi Prince ${ }^{2}$}

Resumo: O presente artigo realizou uma reflexão acerca da importância da disciplina de História no currículo escolar, considerando a sua importância para a construção da identidade e da cidadania, além do desenvolvimento da criticidade. Reconhecemos ainda que, essa disciplina tem a função de resgatar e analisar os aspectos culturais de um determinado povo ou região, objetivando o entendimento do processo de desenvolvimento, considerando que a história analisa o passado, para a compreensão do presente. Nesse contexto, se faz pertinente ressaltar que, ela deve ser ministrada de forma lúdica e contextualizada, para que ocorra a sistematização do processo ensino e aprendizagem.

Palavras-chave: Currículo escolar; História; Educação; Contextualização.

\footnotetext{
${ }^{1}$ História/UNIVAP - Campus Platanus, Brasil. E-mail: vivisfleao@hotmail.com.

2 História/UNIVAP - Campus Platanus, Brasil. E-mail: prince@univap.br.
} 